\title{
Effects of Acute Exercise on Opiate and Cigarette Craving in Methadone Patients
}

\author{
Stephen P. Bailey ${ }^{1, *}$, Eric Hall ${ }^{2}$ and Ayman Fareed ${ }^{3}$ \\ ${ }^{1}$ Departments of Physical Therapy Education \& ${ }^{2}$ Exercise Science, Elon University, Elon, NC 27244, ${ }^{3}$ Department of \\ Psychiatry, Emory University, School of Medicine, Decatur, GA and Atlanta VA Medical Center, Decatur, GA Emory \\ University, School of Medicine, Decatur, GA, USA
}

\begin{abstract}
Acute aerobic exercise has been shown to reduce craving for cigarettes in smokers. Over $80 \%$ of patients enrolled in methadone maintenance treatment (MMT) programs for opiate addiction are smokers and $29 \%$ suffer from diabetes. Many MMT counselors believe that regular physical exercise helps their patients to be successful in the program; however, there have been no previous studies demonstrating that increased physical activity positively impacts MMT patients.
\end{abstract}

Purpose: To determine if acute aerobic exercise changes opiate and cigarette craving in MMT patients.

Methods: 9 MMT patients (Age $=45 \pm 2$ years; BMI=27.5 \pm 1.9$)$ completed 3 randomly applied experimental trials immediately before receiving their daily methadone dose. The experimental trials consisted of 20 minutes of rest, moderate exercise $(65 \%$ predicted maximal heart rate), or vigorous exercise $(80 \%$ predicted maximal heart rate). Craving for opiates, cigarettes, and sweets was recorded before, immediately after (IPE), and 10 minute after exercise (10 Post). Subjects also completed the Subjective Opiate Withdrawal Scale (SOWS) before and 10 minutes after exercise.

Results: Craving for opiates was reduced $(\mathrm{p}<0.05)$ as a result of vigorous exercise at IPE $(-26.8 \pm 6.9 \%)$ and 10 Post $(-5.5 \pm 0.5 \%)$; however, craving for opiates was unchanged following moderate exercise. Craving for cigarettes was reduced $(\mathrm{p}<0.05)$ following both moderate (IPE=-37.9 $\pm 6.1 \% ; 10$ Post=-13.1 $\pm 9.1 \%)$ and vigorous $(\mathrm{IPE}=-37.1 \pm 7.1 \%$; 10 Post $=-8.8 \pm 9.2 \%$ exercise. Craving for sweets and the SOWS was unchanged as a result of exercise.

Conclusion: The results of this investigation suggest that craving for opiates and cigarettes in patients participating in a MMT program may be influenced acute aerobic exercise.

Keywords: Methadone, exercise, craving, smoking.

\section{INTRODUCTION}

In the United States and Europe, 1-2\% of adults report using heroin or other opiates (oxycontin, dilaudid, and hydrocodone) during their lifetime [1]. It is estimated that 1 in 4 people who use opiates become dependent [2]. Once addicted, people may use opiates for decades interspersed by periods of abstinence, treatment, and incarceration [3]. Oral methadone maintenance treatment (MMT) is one of the most common ways to treat opiate addiction. Once enrolled in a MMT program, patients typically receive treatment for at least a year and may receive treatment for years or decades [4]. Regular aerobic exercise has been theorized to be beneficial in the treatment for addiction because of its potential ability to attenuate the physiological responses to stress experienced during withdrawal and positive impact on depression and mood $[5,6]$.

While MMT treatment is effective at protecting these patients from the risks associated with opiate addiction, it

*Address correspondence to this author at the Dpte, Campus Box 2085, Elon University, Elon, NC, 27244; Tel: (336)278-6346; Fax: (336)278-6414;

E-mail: baileys@elon.edu appears that they are at increased risk for other diseases and health behaviors that continue to increase their risk for premature death. One of the most prevalent negative health behaviors of MMT patients is smoking. The rate of cigarette smoking in MMT patients is typically reported to be $80 \%$ or nearly 4 times higher than the rate in the US (20\%) [7]. MMT patients are also heavy smokers consuming approximately 2 packs per day [8]. While most MMT smokers express an interest in quitting smoking ( 75\%), the quit ratio (12\%) (proportion of former to ever smokers) is 4 times less than that seen in US population (50\%) [8]. There is some concern that larger methadone doses may actually increase smoking behavior $[9,10]$. Acute exercise has been shown to reduce cigarette craving in normal smokers [11] and may be effective means to positively influence smoking behavior in MMT patients.

The frequency of diabetes mellitus (DM) in MMT patients is very high. Fareed and colleagues report that $28 \%$ of MMT patients suffer from DM, a rate much higher than that seen in the general population (6.2\%) [12]. These authors also found that $86 \%$ of premature deaths in MMT participants occurred in patients with DM [12]. The exact mechanisms underlying the increased frequency of DM in MMT 
patients is unclear; however, MMT patients have been reported to consume and crave sweets at a much higher level as compared to controls $[13,14]$. There is some limited evidence that acute moderate exercise can reduce the urge to consume chocolate in regular chocolate eaters [15]. As a consequence, it may be possible that exercise could be effectively used to moderate sweet consumption and craving in MMT patients.

MMT patients are typically advised to increase their physical activity by counselors; however, there have been no prior studies investigating the impact of increased physical activity on MMT patients. The purpose of this investigation was to determine if acute aerobic exercise changes opiate and cigarette craving in MMT patients.

\section{METHODS}

\section{Participants}

Nine patients ( 5 men, 4 women; Age $=45 \pm 2$ years; Body Mass Index $=27.5 \pm 1.9)$ enrolled in a Methadone Maintenance Treatment (MMT) program participated in this investigation. Prior to participating in this investigation all subjects read and signed an informed consent form approved by the University's Institutional Review Board (IRB) for Protection of Human Subjects in Research and were screened by a physician. Patients with significant risk of cardiovascular, metabolic, or orthopedic disease were excluded from the investigation. All subjects had been enrolled in MMT for more than 6 months and had been found to be completely compliant with the program for at least 30 days before participation. None of the subjects in this investigation participated in regular physical activity (one time per week) for at least 6 months prior participation in this investigation. All subjects were currently smoking between 15 and 30 cigarettes per day.

\section{Experimental Trials}

For each experimental trial subjects reported to the testing area between 7 and 8 am and 24 hours after their previous methadone dose. After waking, subjects abstained from food consumption, caffeine intake, and smoking until after completion of the experimental trial. Subjects then completed 3 experimental trials consisting of rest (REST), moderate exercise (MOD), or vigorous exercise (VIG). During REST subjects sat in a quiet room with no visual or auditory stimulation. During MOD (65\% predicted maximal heart rate) and VIG (80\% predicted maximal heart rate) subjects exercised on a Monark 828 cycle ergometer at 50 RPMs for 20 minutes [16]. Heart rate was continually monitored during the first 5 minutes of each exercise session and workload was appropriately adjusted to facilitate the desired heart rate response. In an effort to minimize order effects experimental trials were administered using a repeated 3X3 Latin Square Design [17]. Temporary cessation of smoking was confirmed by measurement of carbon monoxide in expired air $(<10$ ppm) using a $\mathrm{Mirco}^{+}$Smokelyzer (Bedfont Scientific Inc, Rochester, Kent, UK).

\section{Instrumentation}

During each trial heart rate (HR), blood pressure (BP), and RPE were recorded before, every ten minutes during exercise, and 10 minutes after exercise. HR was measured using a Polar heart rate monitor. BP was measured using traditional auscultatory techniques. RPE was monitored using the Borg 0-10 scale [18].

Table 1. Physiologic (Heart Rate, SBP:Systolic Blood Pressure, DBP:Diastolic Blood Pressure) and Perceptual (RPE:Rating of Perceived Exertion) Responses to Moderate (MOD, 65\% Predicted Maximal Heart Rate) and Vigorous (VIG, 80\% Predicted Maximal Heart Rate) Exercise in MMT Patients

\begin{tabular}{|c|c|c|c|c|}
\hline Time & Pre & $10 \mathrm{~min}$ & $20 \mathrm{~min}$ & Post $10 \mathrm{~min}$ \\
\hline \multicolumn{5}{|l|}{ Heart Rate } \\
\hline Rest & $73 \pm 5$ & $73 \pm 4$ & $69 \pm 2$ & $68 \pm 3$ \\
\hline MOD & $74 \pm 2$ & $113 \pm 2^{*}$ & $112 \pm 4^{*}$ & $82 \pm 5^{*}$ \\
\hline VIG & $75 \pm 5$ & $130 \pm 7^{*, \#}$ & $134 \pm 8^{*, \#}$ & $89 \pm 7^{*}$ \\
\hline \multicolumn{5}{|l|}{ SBP } \\
\hline Rest & $120 \pm 9$ & $121 \pm 8$ & $119 \pm 9$ & $119 \pm 8$ \\
\hline MOD & $126 \pm 9$ & $149 \pm 12^{*}$ & $148 \pm 13^{*}$ & $120 \pm 10$ \\
\hline VIG & $124 \pm 10$ & $166 \pm 12^{*, *}$ & $171 \pm 15^{*, \#}$ & $121 \pm 17$ \\
\hline \multicolumn{5}{|l|}{ DBP } \\
\hline Rest & $72 \pm 5$ & $70 \pm 4$ & $72 \pm 5$ & $73 \pm 6$ \\
\hline MOD & $73 \pm 5$ & $76 \pm 7$ & $78 \pm 8$ & $76 \pm 6$ \\
\hline VIG & $74 \pm 8$ & $70 \pm 6$ & $73 \pm 5$ & $71 \pm 9$ \\
\hline \multicolumn{5}{|l|}{ RPE } \\
\hline Rest & $\mathrm{n} / \mathrm{a}$ & $\mathrm{n} / \mathrm{a}$ & $\mathrm{n} / \mathrm{a}$ & $\mathrm{n} / \mathrm{a}$ \\
\hline MOD & $\mathrm{n} / \mathrm{a}$ & $4 \pm 1$ & $5 \pm 2$ & $\mathrm{n} / \mathrm{a}$ \\
\hline VIG & $\mathrm{n} / \mathrm{a}$ & $7 \pm 2^{\#}$ & $8 \pm 1^{\#}$ & $\mathrm{n} / \mathrm{a}$ \\
\hline
\end{tabular}

"Indicates difference from Rest, ${ }^{*}$ Indicates difference from MOD. 


\section{Craving for Opiates, Cigarettes, \& Sweets}

Craving for opiates, cigarettes, and sweets was measured before, immediately after, and 10 minutes after exercise by a visual analog scale (VAS) using $100 \mathrm{~mm}$ line anchored on the left with "No Craving" and the right with "Extreme Craving". Single item assessment of craving assessment using a VAS has been reliable and response for a variety of substances $[19,20]$. Subjects were asked to make a mark on the line that represents their perception of their current state of craving for the substance. Similarly, the Subjective Opiate Withdrawal Scale (SOWS) [21] was used to measure symptoms of opiate withdrawal. The SOWS is a 16-item self-report scale. Responses to each item are made using a 5-point Likert-type scale (ranging from $0=$ 'Not At All' to $5=$ 'Extremely').

\section{Data Analyses}

A 2-way (Time $\mathrm{x}$ Condition) multivariate analysis of variance (MANOVA) was conducted to determine if there were any differences across the different exercise conditions. Significance was set a priori at the $p<0.05$ level. When significant main effects were observed a Newman-Keuls
Multiple-Comparison Test was performed. For all values, means \pm SE are reported in the text or presented in a table or figure. All statistical analyses were completed using Number Crunchers Statistical Software (NCSS; Version 07.1.19; Kaysville, UT).

\section{RESULTS}

Physiologic and perceptual responses to exercise are described in Table $\mathbf{1}$.

Craving for opiates and cigarettes was impacted by exercise conditions. MANOVA demonstrated a significant across exercise conditions across opiates $\left(\mathrm{F}_{2,48}=4.99, \mathrm{p}=0.017\right)$ and cigarettes $\left(\mathrm{F}_{2,48}=13.95, \mathrm{p}<0.001\right)$. Specifically, craving for opiates was reduced immediately after exercise and 10 minutes after exercise only during VIG exercise condition (Fig. 1). In contrast, craving for cigarettes was reduced at these same time points during both the MOD and VIG exercise conditions (Fig. 2). Craving for sweets did not change from rest (Rest $=22 \pm 9 \mathrm{~mm} ; \quad M O D=38 \pm 7 \mathrm{~mm}$; $\mathrm{VIG}=34 \pm 6 \mathrm{~mm})$ to immediately after exercise (Rest $=29 \pm 12$ $\mathrm{mm}$; MOD $=30 \pm 9 \mathrm{~mm}$; VIG $=25 \pm 10 \mathrm{~mm})$ to 10 minutes after exercise $($ Rest $=35 \pm 5 \mathrm{~mm} ; \mathrm{MOD}=24 \pm 7 \mathrm{~mm} ; \mathrm{VIG}=38 \pm 9 \mathrm{~mm})$

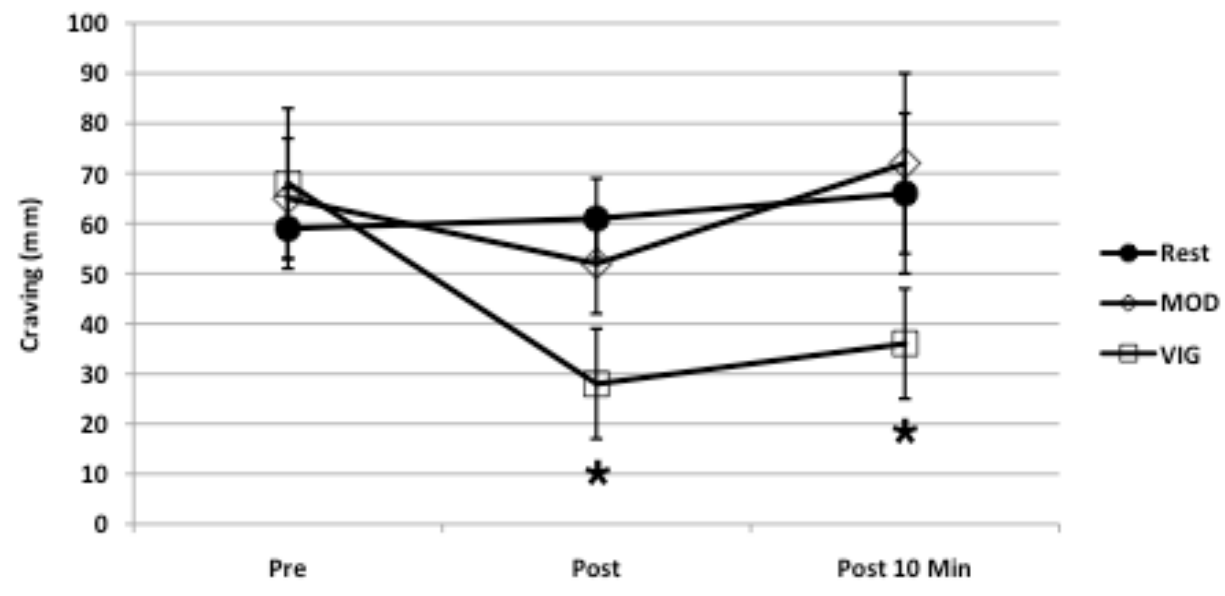

Fig. (1). Impact of acute exercise on opiate craving in MMT patients.

*Indicates difference from rest \& MOD in VIG $(\mathrm{p}<0.05)$.



Fig. (2). Impact of acute exercise on craving for cigarettes in MMT patients.

*Indicates difference from rest in MOD \& VIG $(\mathrm{p}<0.05)$. 
under any condition $\left(\mathrm{F}_{2,48}=1.54, \mathrm{p}=0.231\right)$. Similarly, the SOWS did not change from pre (Rest=6.6 $\pm 1.8 ; \mathrm{MOD}=6.0 \pm 2.1$; $\mathrm{VIG}=7.4 \pm 1.2$ ) to 10 minutes after exercise (Rest $=6.0 \pm 2.7$; $\mathrm{MOD}=8.4 \pm 1.2 ; \mathrm{VIG}=7.2 \pm 1.9)$ under any condition $\left(\mathrm{F}_{2,48}=1.78\right.$, $\mathrm{p}=0.202$ ).

\section{DISCUSSION}

Acute exercise reduced cravings for cigarettes in MMT patients immediately after exercise and the changes were maintained 10 minutes after exercise. These findings are similar in direction and magnitude to those described by many investigators in "normal" smokers [11]. The mechanisms underlying these positive changes are unclear; however, it is possible that acute exercise reduced craving for cigarettes by distraction, reducing stress, and/or some undetermined neurophysiological mechanism.

There have been few investigations that have explored the effects of varying exercise intensities on cigarette craving in smokers. In this investigation, exercise at $80 \%$ of predicted maximal heart rate was no more effective at reducing craving for cigarettes than exercise at $65 \%$. These findings are similar to those described by Pomerleau and colleagues [22] (30\% versus $\left.80 \% \mathrm{VO}_{2} \mathrm{max}\right)$, Everson and colleagues $[23,24]$ (44\% versus $55 \%$ age-predicted maximal heart rate and $40-59 \%$ versus $60-84 \%$ heart rate reserve), and Scerbo and colleagues [25]. Taken together these findings suggest that the change in craving for cigarettes following exercise in MMT patients is similar to that typically observed in "normal" smokers. While the mechanisms underlying these changes remain unclear, it seems important to recognize that exercise intensity does not appear to have a varying effect on craving to smoke. It is somewhat challenging to interpret the impact of exercise intensity on smoking craving in this and other investigations because of the methodologies used to establish exercise intensity. Affective responses to exercise above ventilatory threshold (VT) tend to be negative and tend to be positive to exercise below VT [26]. It seem very possible that at least some of the subjects exercising at the higher intensities used in the investigations described above were exercising above VT causing a more varied and possibly negative affective response to exercise. In the future, it may be appropriate to develop experimental designs where all exercise intensities are made relative to VT. Despite these concerns, it seems reasonable to conclude that acute exercise of any intensity may be a valuable strategy to modify smoking behavior in MMT patients.

Acute exercise has also been shown to reduce smoking behavior. Information about the impact of acute exercise in MMT patients on smoking behavior (e.g. time to ad libitum smoking) was not collected in this investigation and should be included in future investigations. Future investigations in this population should also observe these measures and measures of cigarette craving for longer periods of time after exercise (>10 minutes) than used in this investigation. This information would be valuable when developing strategies to use acute exercise to modify smoking behavior in MMT patients.

Craving for opiates in MMT patients was reduced as a consequence of vigorous exercise and was unchanged as a result of moderate exercise. As far as we are aware, this is the first investigation that has described changes in opiate craving as a result of exercise in people suffering from opiate addiction. The only similar finding, was described by Mclachlan and colleagues [27]. These authors found that voluntary exogenous opiate consumption was lower in exercising versus sedentary rats. Potential mechanisms underlying the positive effect of acute exercise on opiate craving are unknown. Some have speculated that it might be possible that exercise could replace or mimic some of the neurophysiologic events associated with exogenous opiate consumption and reduce the craving for exogenous opiates. This hypothesis is purely conjecture at this point and significant work needs to be done to describe the neurophysiologic events associated with exercise in the opiate addiction environment. It seems just as plausible that the psychological mechanisms proposed for changes in cigarette craving after acute exercise (i.e. distraction and stress reduction) are playing a role in changes in opiate craving.

No changes in cravings for sweets or symptoms of opiate withdraw were observed as a consequence of acute exercise. There have been some limited reports of increased sweet intake and preference towards sweets in MMT patients compared to controls $[13,14]$; however, this investigation provides no evidence to suggest that acute exercise could influence consumption of sweets in this population. These findings are somewhat in contrast to those of Taylor and Oliver [15] who found cravings for chocolate to be reduced in regular chocolate users following a 15 minute brisk walk. These investigators introduced a strong cue (opening a wrapped chocolate bar) before assessing craving and it is possible that the more passive nature of this investigation was not able to detect changes in sweet cravings. More importantly, the lack of changes in sweet cravings along with the changes in smoking and opiate cravings suggest that acute exercise does not have a global impact of craving for consumption of all substances. The baseline cravings for sweets were low compared to the baseline cravings for cigarettes and opiates. Perhaps acute exercise is only valuable in altering cravings for the most desirable substances for the individual. Similarly, the baseline SOWS measures in this investigation were low. These low baseline measures suggest that, in this chronically treated and stable MMT population, a 24 hour period following the previous methadone dose was not long enough to precipitate significant withdraw symptoms. Use of the SOWS in an acute exercise environment to measure symptoms withdraw is also problematic because interpretation of several of the items by the subject could be influenced by physical activity.

\section{CONCLUSIONS}

Acute exercise apparently reduced cravings for opiates and cigarettes in MMT patients for a short period of time. The mechanisms that precipitated this response are unclear and should be investigated in the future. Acute aerobic exercise may be beneficial to MMT patients to reduce cigarette smoking and the risk illicit opiate consumption.

\section{CONFLICTS OF INTEREST}

None declared.

\section{ACKNOWLEDGEMENT}

None declared. 


\section{REFERENCES}

[1] Substance Abuse and Mental Health Services Administration, Office of Applied Studies. Treatment Episode Data Set (TEDS). Highlights - 2006. National Admissions to Substance Abuse Treatment Services DASIS Series: S-40, DHHS Publication No. (SMA) 08-4313, Rockville, MD 2008.

[2] Anthony JC, Warner L, Kessler R. Comparative epidemiology of dependence on tobacco, alcohol, controlled substances, and inhalants: basic findings from the national comorbidity survey. Exp Clin Psychopharmacol 1994; 2(3): 244-68.

[3] Goldstein A, Herrera J. Heroin addicts and methadone treatment in albuquerque: a 22-year follow up. Drug Alcohol Depend 1995; 40(2): 139-50

[4] Marion IJ. Methadone treatment at forty. Sci Pract Perspect 2005; 3(1): 25-33.

[5] Blumenthal JA, Babyak MA, Doraiswamy PM, et al. Exercise and pharmacotherapy in the treatment of major depressive disorder. Psychosom Med 2007; 69(7): 587-96.

[6] Brown RA, Abrantes AM, Read JP, et al. A pilot study of aerobic exercise as an adjunctive treatment for drug dependence. Ment Health Phys Act 2010; 3(1): 27-34.

[7] Ussher M, Taylor A, Faulkner G. Exercise interventions for smoking cessation. Cochrane Database Syst Rev 2008; 8(4): CD002295.

[8] Richter KP, Gibson CA, Ahluwalia JS, Schmelzle KH. Tobacco use and quit attempts among methadone maintenance clients. Am J Public Health 2001; 91(2): 296-9.

[9] Chait LD, Griffiths RR. Effects of methadone on a human cigarette smoking and subjective ratings. J Pharmacol Exp Ther 1984; 229(3): 636-40.

[10] Stark MJ, Campbell BK. Cigarette smoking and methadone dose levels. Am J Drug Alcohol Abuse 1993; 19(2): 209-17.

[11] Taylor AH, Ussher MH, Faulkner G. The acute effects of exercise on cigarette cravings withdrawal symptoms, affect and smoking behavior: a systematic review. Addiction 2007;102: 534-43.

[12] Fareed A, Casarella J, Amar R, Vayalapalli S, Drexler K. Benefits of retention in methadone maintenance and chronic medical conditions as risk factors for premature death among older heroin addicts. J Psychiatr Pract 2009; 15(3): 227-34.

[13] Kolarzyk E, Jenner B, Szpanowska-Wohn A, Pach D, Szurkowska $M$. The changes in taste preferences during 4 years period of methadone maintenance treatment. Prz Lek 2005; 62(6): 378-81.
[14] Nolan LJ, Scagnelli LM. Preference for sweet foods and higher body mass index in patients being treated in long-term methadone maintenance. Subst Use Misuse 2007; 42(10): 1555-66.

[15] Taylor A, Oliver AJ. Acute effects of brisk walking on urges to eat chocolate, affect, and responses to a stressor and chocolate cue. An experimental study. Appetite 2009; 52: 155-60.

[16] ACSM's guidelines for exercise testing and prescription. $7^{\text {th }}$ ed. Baltimore: Lippincott Williams \& Wilkins 2005.

[17] Hicks CR. Fundamental concepts in the design of experiments. $3^{\text {rd }}$ ed. Orlando, FL: Saunders College Publishing 1982.

[18] Borg G. Borg's perceived exertion and pain scales. Stockholm: Human Kinetics 1998

[19] Niaura R, Shadel WG, Abrams DB, Monti PM, Rohsenow DJ, Sirota A. Individual differences in cue reactivity among smokers trying to quit: effects of gender and cue type. Addict Behav 1998; 23(2): 209-24.

[20] Sayette M A, Shiffman S, Tiffany ST, Niaura RS, Martin CS, Shadel WG. The measurement of drug craving. Addiction 2000; 95(Suppl. 2): S189-S210.

[21] Handelsman L, Cochrane KJ, Aronson MJ, et al. Two new rating scales for opiate withdrawal. Am J Drug Alcohol Abuse 1987; 13(3): 293-308.

[22] Pomerleau OF, Scherzer HH, Grunberg NE, et al. The effects of acute exercise on subsequent cigarette smoking. J Behav Med 1987; 10: 117-27.

[23] Everson ES, Daley AJ, Ussher M. Does exercise have an acute effect on desire to smoke, mood and withdrawal symptoms in abstaining adolescent smokers? Add Behav 2006; 31: 1547-58.

[24] Everson ES, Daley AJ, Ussher M. The effects of moderate and vigorous exercise on desire to smoke, withdrawal symptoms and mood in abstaining young adult smokers. Ment Health Phys Act 2008; 1(1): 26-31.

[25] Scerbo F, Faulkner G, Taylor A, Thomas S. Effects of exercise on cravings to smoke: The role of exercise intensity and cortisol. Sports Sci 2010; 28(1): 11-9.

[26] Ekkekakis P, Hall EE, Petruzzello SJ. The relationship between exercise intensity and affective responses demystified: to crack the 40-year-old nut, replace the 40-year-old nutcracker. Ann Behav Med 2008; 35(2): 136-49.

[27] McLachlan CD, Hay M, Coleman GJ. The effects of exercise on the oral consumption of morphine and methadone in rats. Pharmacol Biochem Behav 1994; 48(2): 563-8.

(C) Bailey et al.; Licensee Bentham Open.

This is an open access article licensed under the terms of the Creative Commons Attribution Non-Commercial License (http://creativecommons.org/licenses/ by-nc/3.0/) which permits unrestricted, non-commercial use, distribution and reproduction in any medium, provided the work is properly cited. 